\title{
A Systematic Review of Vancomycin Dosing in Patients with Hematologic Malignancies or Neutropenia
}

This article was published in the following Dove Press journal: Infection and Drug Resistance

\author{
$\mathrm{Na} \mathrm{He}$ iD $^{1,2}$ \\ Fei Dong ${ }^{3}$ \\ Wei Liu (D)' \\ Suodi Zhai' \\ 'Department of Pharmacy, Peking \\ University Third Hospital, Beijing, \\ People's Republic of China; ${ }^{2}$ Department \\ of Pharmacy Administration and Clinical \\ Pharmacy, School of Pharmaceutical \\ Science, Peking University, Beijing, \\ People's Republic of China; ${ }^{3}$ Department \\ of Hematology, Peking University Third \\ Hospital, Beijing, People's Republic of \\ China
}

Objective: To provide a comprehensive review of vancomycin dosing in patients with hematologic malignancies or neutropenia.

Methods: PubMed, Embase and the Cochrane Library were searched through April 2, 2020. Original studies relevant to vancomycin dosing regimen in adults with hematologic malignancies or neutropenia were included. No restriction was applied in study design and language. A descriptive analysis was performed.

Results: Twenty-three studies were included eventually, of which eighteen were case series studies, four were cohort studies and another one was a randomized controlled trial. Five case series studies made a clinical audit of conventional vancomycin dosing in patients with malignancies or neutropenia, showing that the proportion of patients with sub-therapeutic trough levels remained high, ranging from $32 \%$ to $88 \%$. Seven case series studies and four cohort studies demonstrated that vancomycin clearance (CLva) tended to be higher in patients with hematologic malignancies or neutropenia, whereas volume of distribution (V) seemed to be comparable to the control group. Five studies proposed individualized initial dosing regimen per the pharmacokinetic changes; however, no prospective validation has been conducted in clinical setting. Additionally, four case series studies suggested that the correlation between vancomycin clearance and estimated creatinine clearance was relatively poor, bringing a great challenge to proper dosing strategy. A randomized controlled trial stated that therapeutic drug monitoring (TDM) of vancomycin could decrease the incidence of nephrotoxicity in immunocompromised febrile patients with hematologic malignancies.

Conclusion: The available evidence indicates that conventional vancomycin dosing leads to suboptimal concentration in patients with hematologic malignancy or neutropenia. TDM accompanied by pharmacokinetic interpretation can decrease the risk of nephrotoxicity. The individualization of the initial dosing regimen and mechanisms of augmented clearance require further research.

Keywords: vancomycin, hematologic malignancy, neutropenia, pharmacokinetics, evidencebased practice

\section{Introduction}

A proper dosing regimen is the cornerstone of antimicrobial therapy, which has a great impact on treatment outcome, development of drug resistance as well as dose-dependent toxicity. Traditionally, the use of reduced doses in patients with renal impairment has been widely accepted. Dosage adjustments for patients with renal failure have been listed in labels of various medications and relevant clinical guidelines. ${ }^{1,2}$ However, more and more studies have underlined the
Correspondence: Suodi Zhai; Wei Liu Department of Pharmacy, Peking University Third Hospital, 49 Huayuan North Road, Haidian District, Beijing 100191, People's Republic of China Tel +86 I0-82266686; +86 I0-82265740 Email zhaisuodi@I63.com; andthen0023@163.com
Infection and Drug Resistance 2020:13 |807-|82|

1807 
existence of augmented renal clearance (ARC), especially in critically ill patients, ${ }^{3}$ patients with brain injury $^{4}$ and neurosurgery, ${ }^{5}$ which could result in antibiotics' sub-therapeutic concentrations and poorer outcomes. In this case, an assumption could be made that dosing regimens should be optimized according to the degree of increase in renal function, similar to the downward dose adjustments in patients with renal dysfunction.

Risk of infections will increase in patients with neutropenia, which occurs frequently after chemotherapy for cancer, especially hematologic malignancies. ${ }^{6}$ Therefore, the administration of optimal antibiotics was recommended in clinically or microbiologically documented infections. ${ }^{7}$ Additionally, patients with hematologic malignancies or neutropenia have been reported to have enhanced renal clearance, ${ }^{8,9}$ which would affect the systematic exposure of antibiotics predominately excreted through urine, including the commonly used anti-pseudomonas beta-lactams, aminoglycosides and vancomycin. Hence, the optimization of dosing regimens' might also be required under the circumstance.

To our knowledge, vancomycin is one of the most well-studied antibiotics with respect to therapeutic drug monitoring (TDM). ${ }^{2,10,11}$ In spite of the potential changes in pharmacokinetic parameters and possible clinical failure proposed in patients with hematologic malignancies or neutropenia, ${ }^{8,9}$ neither increased dosing regimen nor TDM of vancomycin has been recommended in these patients, implying that the evidence was insufficient or the integration of evidence into practice should be strengthened. Notably, no comprehensive review has been conducted on this issue.

The objective of this study was to gain an in-depth understanding of the current status of vancomycin dosing regimen, pharmacokinetics and optimization of vancomycin dosing in patients with hematologic malignancies or neutropenia, which could be of great value for clinical practice and identifying knowledge gaps for future research.

\section{Methods}

We conducted this systematic review using the Preferred Reporting Items for Systematic Reviews and MetaAnalyses (PRISMA) guidelines. ${ }^{12}$

\section{Data Sources and Searches}

PubMed, Embase and the Cochrane Library were searched from their respective inception to July 26th., 2018. A complementary search was also performed to identify the most recent articles (published before April 2, 2020). The search terms included hematologic malignancy, neutropenia and vancomycin. Both mesh terms and text words were used. The search strategy is detailed in Tables S1-S3 . Reference lists of the retrieved articles and related reviews were also examined manually for additional studies.

\section{Eligibility Criteria}

All records that comprised of adult patients with hematologic malignancies or neutropenia were included. When the proportion of hematologic malignancies or neutropenia was greater than $80 \%$ in one individual arm, the arm could be assumed to be patients with hematologic malignancies or neutropenia, respectively. Furthermore, all the patients were required to receive intravenous vancomycin. Outcomes should involve at least one of the followings: vancomycin serum concentration, pharmacokinetic (PK) parameters, vancomycin dosing, clinical response and nephrotoxicity. The exclusion criteria were as follows: (1) insufficient clinical data; (2) study types were cases, reviews or editorials; (3) the analysis was not relevant to vancomycin dosing regimen; (4) duplicate publication. No restriction was applied in language.

\section{Study Selection}

Two reviewers (N. H. and W. L.) screened titles and abstracts per the eligibility criteria to identify potential publications independently at first. Then, the full text was assessed for final inclusion. Any disagreement was resolved by discussion between the 2 reviewers or by consulting a third reviewer (S. Z.).

\section{Data Extraction}

A pre-specified data form was used to extract the following information: study characteristics (the first author's name, year of publication, study design, country, sample size), patients' baseline characteristics (characteristics of patients included, proportion of patients with neutropenia, gender, age, weight, renal function), vancomycin dosing, timing of vancomycin serum concentration sampling, outcomes of interest. The data 
extraction was performed by one reviewer (N. H.) and checked by another reviewer (W. L.). Discrepancies were addressed by discussion between two reviewers or consultation with the third reviewer (S. Z.) if necessary.

\section{Quality Assessment}

The methodological quality of each included study was assessed by 2 reviewers (N. H. and X. L.) independently, and disagreements were resolved by discussion. The potential risk of bias in the randomized controlled trials was assessed using Cochrane risk of bias. ${ }^{13}$ The quality of cohort studies was assessed per the Newcastle-Ottawa Scale (NOS) scale. ${ }^{14}$ Concerning case series studies, we used National Institutes of Health (NIH) Quality Assessment Tool (https://www.nhlbi.nih.gov/health-topics /study-quality-assessment-tools). As no validated tool for pharmacokinetic studies was available, we used the ClinPK Statement, a reporting guideline for clinical pharmacokinetic studies to assess their quality. ${ }^{15}$

\section{Data Analysis}

To summarize all the information concerning vancomycin dosing in patients with hematologic malignancies or neutropenia, a descriptive analysis was performed.

\section{Results}

Of the 6404 potentially relevant published reports identified, 46 reports proved potentially eligible after duplicates removed and abstracts screened. On full-text screening, 23 studies were ultimately included in the systematic review (Figure 1). The list of the excluded studies in the process of full-text screening is detailed in Table S4.

The basic characteristics of the included studies can be found in Table S5. All the 23 studies $^{16-38}$ were published in English, of which three ${ }^{16,18,19}$ were conference abstracts. One study $^{33}$ was a simulation study without an actual clinical data. Two studies ${ }^{20,32}$ adopted the same set of data with different analyses methods. Therefore, twenty-one sets of clinical data were finally included. In 18 studies, ${ }^{17,18,20,22-31,34-38}$ vancomycin was infused intermittently, and 2 studies adopted continuous infusion, ${ }^{19,21}$ whereas the remaining 1 conference abstract did not report the specific dosing regimen. ${ }^{16}$ For single-arm studies, nine studies included neutropenic hematologic patients consecutively, ${ }^{16,18,20,21,26,28,31,34,35}$ while 6 studies included patients with hematologic

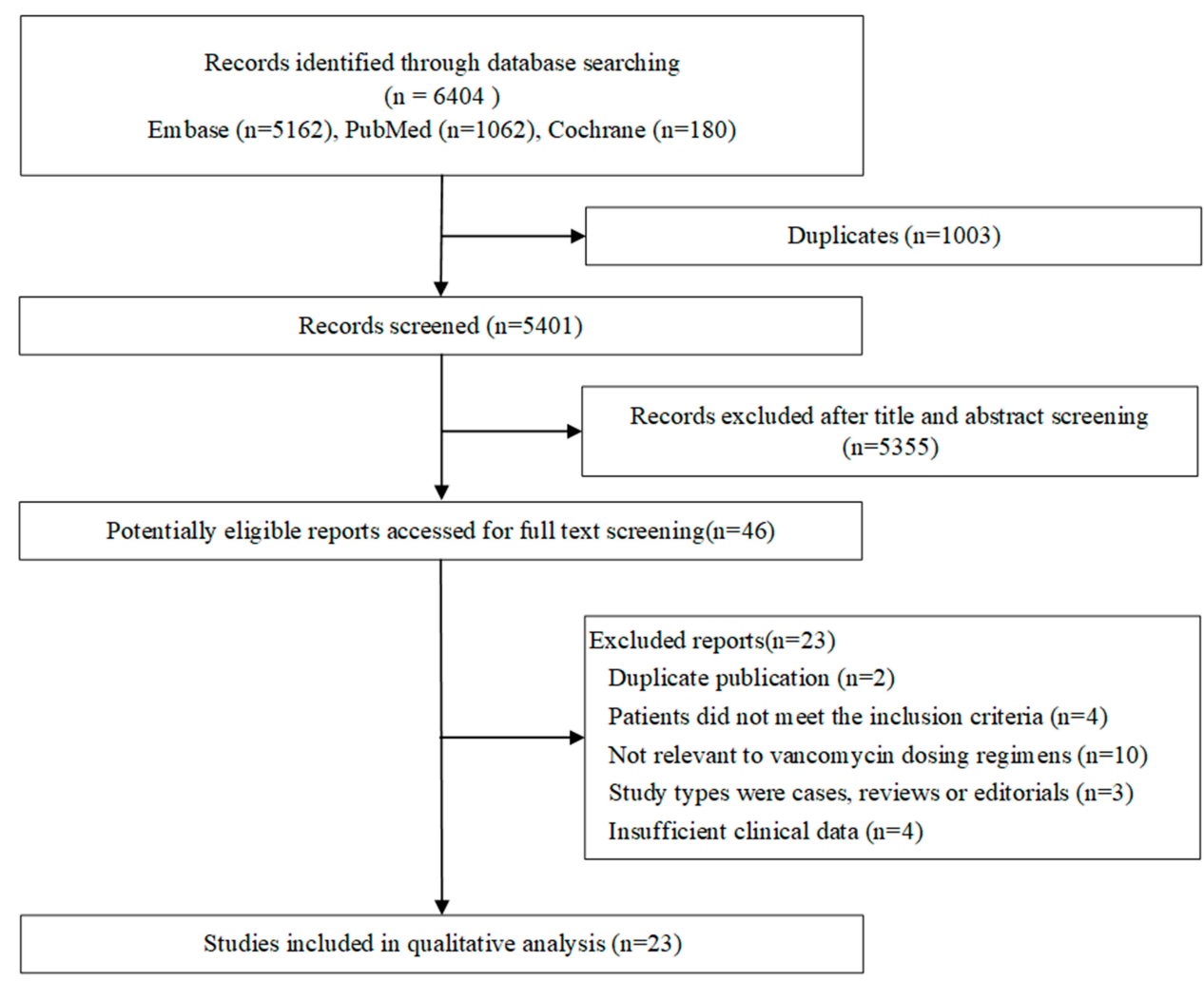

Figure I Flow chart of study selection. 
malignancies without distinguishing neutropenia from non-neutropenia. ${ }^{17,19,22,27,29,38}$ Additionally, another two studies included hospitalized patients and took neutropenia as a risk factor. ${ }^{30,36}$ Concerning comparative cohort studies, there were two studies comparing neutropenic patients with nonneutropenic patients, ${ }^{23,25}$ and another 2 studies focused on the difference between hematologic malignant patients and control groups. ${ }^{24,37}$

Concerning the quality assessment of these included studies, 4 studies were not assessed, of which $3^{16,18,19}$ were conference abstracts and one ${ }^{33}$ was a simulation pharmacokinetic study. The detailed results of quality assessment are shown in Tables S6-S9. Overall, included studies were of adequate quality.

All the included studies were classified according to their objectives as follows:

\section{Clinical Audit of Vancomycin Dosing}

Seven studies ${ }^{16-22}$ aimed to make a clinical audit of conventional vancomycin dosing in patients with hematologic malignancies or neutropenia. The characteristics and summary of results in each study are listed in Table 1. Six studies reported the proportion of patients with sub-therapeutic concentrations in routine clinical care, and five of which reported value ranging from $32 \%$ to $88 \%$. However, Vazin et $\mathrm{al}^{22}$ did not report the specific vancomycin dosing, yielding result $(3.6 \%)$ that differed significantly from other 5 studies. Furthermore, Vermis et $\mathrm{al}^{19}$ stated that to attain therapeutic vancomycin levels, vancomycin maintenance dose $(41.7 \mathrm{mg} / \mathrm{kg} / \mathrm{d}$ vs. $32.7 \mathrm{mg} / \mathrm{kg} / \mathrm{d}$ ) was significantly higher when ARC (estimated $\mathrm{CL}_{\mathrm{CR}}$ greater than $120 \mathrm{~mL} / \mathrm{min}$ ) was present in hematologic malignant patients. Overall, vancomycin concentrations following conventional dosage were insufficient in patients with hematologic malignancies or neutropenia.

\section{The Potential Change in Pharmacokinetic \\ Parameters}

\section{Comparative Studies Between Patients with Hematologic Malignancies or Neutropenia and Control Groups}

Two studies ${ }^{23,25}$ were comparative cohort studies between neutropenic patients and non-neutropenic patients, and another 2 studies ${ }^{24,37}$ focused on the difference between patients with hematologic malignancies and the control group. The characteristics of the four studies are summarized in Table 2.
Although both neutropenic patients and the control group applied the standard dosage and consistent sampling time in Choi et al, ${ }^{23}$ the median serum vancomycin concentration was lower in neutropenic patients than the control group $(9.1 \mathrm{mg} / \mathrm{L}$ vs. $12.1 \mathrm{mg} / \mathrm{L}, P<0.0001)$. Multiple logistic regression analysis still revealed a significant association between sub-therapeutic vancomycin concentration (trough serum concentration $<10$ $\mathrm{mg} / \mathrm{L}$ ) and neutropenia (odds ratio [OR]: 1.75; $P=0.029$ ).

Additionally, Haeseker et $\mathrm{al}^{25}$ primarily investigated neutropenia and hematologic malignancy's effect on pharmacokinetic parameters, whereas Al-Kofide et $\mathrm{al}^{24}$ and Izumisawa et $\mathrm{al}^{37}$ focused on the effect of hematologic malignancy. Concerning specific pharmacokinetic parameters, vancomycin clearance (CLva) was higher in patients with hematologic malignancies or neutropenia (Table 3). However, the results for volume of distribution (V) were still conflicting (Table 3). Notably, five patients in Haeseker et $\mathrm{al}^{25}$ received vancomycin in both neutropenic and nonneutropenic period and presented a reversible augmented CLva in the nonneutropenic period $(91 \pm 26 \mathrm{~mL} / \mathrm{min}$ vs. $45 \pm 10 \mathrm{~mL} / \mathrm{min}, P=0.009)$.

\section{Development and Validation of PK Models}

Although seven studies ${ }^{20,26-29,36,38}$ calculated vancomycin's pharmacokinetic parameters in patients with hematologic malignancies or neutropenia, only three studies $^{29,36,38}$ used non-linear mixed effects modelling. The characteristics and PK parameter of studies included are listed in Table 4, showing a marked difference in CLva from those reported for patients with nonhematologic malignancy and non-neutropenia. ${ }^{39,40}$ Notably, one study ${ }^{36}$ included neutropenia as one of the covariates affecting vancomycin clearance, of which vancomycin clearance is increased in patients with neutropenia by $27.7 \%$. Nevertheless, $V$ seemed to be comparable to normal controls without hematologic malignancy and neutropenia. ${ }^{39,40}$ Additionally, all the PK parameters had great inter-individual variation among patients with hematologic malignancies or neutropenia.

\section{The Potential Effect of Neutropenia on Creatinine Clearance $\left(\mathrm{CL}_{\mathrm{CR}}\right)$}

Four studies ${ }^{25,28,30,31}$ reported the potential effect of neutropenia on $\mathrm{CL}_{\mathrm{CR}}$. Hirai et $\mathrm{al}^{30}$ conducted a single-center retrospective study in 292 patients with normal serum 
creatinine concentration, and demonstrated that febrile neutropenia was an independent risk factor of ARC (OR: 2.76; 95\% CI: 1.11-6.67; $P=0.0254)$. However, Haeseker et $\mathrm{al}^{25}$ showed that the estimated $\mathrm{CL}_{\mathrm{CR}}$ was not significantly different between patients with neutropenia and non-neutropenia (Table 2).

Three studies evaluated the correlation between CLva and estimated $\mathrm{CL}_{\mathrm{CR}}$ solely. Soto et $\mathrm{al}^{31}$ included 45 neutropenic $\left(<1000 / \mathrm{mm}^{3}\right)$ hematologic patients and demonstrated that the correlation coefficient between CLva $(106 \pm 37 \mathrm{~mL} / \mathrm{min})$ and estimated $\mathrm{CL}_{\mathrm{CR}}(84.7 \pm$ $32 \mathrm{~mL} / \mathrm{min}$ ) was 0.42 . Le Normand et $\mathrm{al}^{28}$ illustrated a poor correlation in neutropenic patients $\left(100 / \mathrm{mm}^{3}\right)$ as well ( $\mathrm{n}=10, r=0.281$ ). According to Hirai et al, ${ }^{30}$ the non-ARC patients showed a significant correlation between $\mathrm{CL}_{\mathrm{CR}}$ ad CLva $(r=0.8726, P<0.0001)$; however, no such relationship was observed in patients with ARC $(r=0.1029, P=0.4866)$.

Above all, although $\mathrm{CL}_{\mathrm{CR}}$ possibly has an increase in patients with neutropenia, estimated $\mathrm{CL}_{\mathrm{CR}}$ itself could not identify the specific patients with ARC, which brought difficulty to the prediction of CLva.

\section{Optimization of Initial Vancomycin Dosing Regimen}

Six studies ${ }^{24,25,32,33,36,38}$ were relevant to the optimization of initial vancomycin dosing regimen. TaghizadehGhehi et $\mathrm{al}^{32}$ evaluated the applicability of the most cited vancomycin one-compartment models developed in common patients using data from their recent study. $^{20}$ They demonstrated that none of the seven pharmacokinetic models performed well to calculate initial vancomycin dosage in Iranian patients underwent hematopoietic stem cell transplantation. Using a published population pharmacokinetic (PPK) model $^{29}$ in patients with hematologic malignancies, Fernandez et $\mathrm{al}^{33}$ performed Monte Carlo simulation to calculate vancomycin dosages required in the specific subpopulation. When standard vancomycin dosing (2000 $\mathrm{mg} / \mathrm{d})$ was given, cumulative fraction of response (CFR) for $S$. aureus was $90.4 \%, 47.3 \%$ and $31.2 \%$ for $\mathrm{CL}_{\mathrm{CR}}$ values of $<60,60-120$ and $>120 \mathrm{~mL} /$ min, respectively. If a CFR of $80 \%$ was considered to be clinically appropriate, vancomycin doses of 3000 and $4000 \mathrm{mg} / \mathrm{d}$ for a $\mathrm{CL}_{\mathrm{CR}} 60-120$ and $>120 \mathrm{~mL} / \mathrm{min}$ should be used. Okada et $\mathrm{al}^{38}$ also proposed a vancomycin dosing nomogram in patients undergoing allogeneic hematopoietic stem-cell transplantation based on PPK model and Monte Carlo simulation. Suggested vancomycin dosing is $1 \mathrm{~g}$ per 12 hours when $\mathrm{CL}_{\mathrm{CR}}$ ranging from 75 to $90 \mathrm{~mL} / \mathrm{min}, 0.75 \mathrm{~g}$ per 8 hours when $\mathrm{CL}_{\mathrm{CR}}$ ranging from 90 to $120 \mathrm{~mL} / \mathrm{min}, 1 \mathrm{~g}$ per 8 hours when $\mathrm{CL}_{\mathrm{CR}}$ ranging from 120 to $175 \mathrm{~mL} /$ min, and $1.25 \mathrm{~g}$ per 8 hours for $\mathrm{CL}_{\mathrm{CR}}$ greater than $175 \mathrm{~mL} / \mathrm{min}$. Based on individualized pharmacokinetic parameters calculated by AI-Kofide et al, ${ }^{24}$ the actual dosing regimen for cancer patients should be $60 \mathrm{mg} / \mathrm{kg} /$ day, which doubled the required dose for the general population $(30 \mathrm{mg} / \mathrm{kg} / \mathrm{d})$. Haeseker et $\mathrm{al}^{25}$ demonstrated that to achieve the same $\mathrm{AUC}_{24}$, the mean dosage in patients with neutropenia was significantly higher than the control group $(2017 \pm 720$ vs $1521 \pm 727 \mathrm{mg}$, $P<0.001)$. In this case, they concluded that the daily dose should be increased with $33 \%$ in patients with neutropenia (from $15 \mathrm{mg} / \mathrm{kg}$ twice daily to $13 \mathrm{mg} / \mathrm{kg}$ three times daily). Similarly, another study ${ }^{36}$ suggested a $25 \%$ increase for vancomycin dosing in neutropenic patients. However, the dosing algorithms aforementioned were inconsistent to some extent and have not been validated in the prospective clinical setting. Hence, no simple upward dose adjustment can be put up with great validity and the initial dosing recommendation still remains investigational.

\section{Evaluation and Implementation of Vancomycin TDM}

Two aspects of TDM have been explored before, including the target trough concentration and the evaluation of TDM-guided vancomycin therapy. Suzuki et $\mathrm{al}^{35}$ retrospectively included 63 febrile neutropenic patients with hematologic malignancies and investigated the association of first trough concentration at steady state with clinical efficacy and nephrotoxicity. They proposed that the cut-off value of vancomycin trough concentration should be around $11.5 \mathrm{mg} / \mathrm{L}$ in these patients.

To assess the effectiveness and safety of vancomycin TDM and pharmacokinetic interpretation, Fernandez et $\mathrm{al}^{34}$ performed a prospective randomized study in 70 immunocompromised febrile patients with hematologic malignancies. Although there was no significant difference in clinical response rate and duration of fever between TDM-guided group $(n=37)$ and control group $(n=33)$, the incidence of nephrotoxicity significantly decreased $(13.5 \%$ vs. $42.4 \%, P<0.05)$. 
Table I Studies with Clinical Audit of Vancomycin Dosing

\begin{tabular}{|c|c|c|c|c|c|c|c|}
\hline $\begin{array}{l}\text { Author } \\
\text { (Year) }\end{array}$ & Country & $\begin{array}{l}\text { Study } \\
\text { Design }\end{array}$ & $\begin{array}{l}\text { Characteristics of Patients } \\
\text { Included }\end{array}$ & $\begin{array}{l}\text { Patients with } \\
\text { Neutropenia } \\
\text { (\%) }\end{array}$ & $\begin{array}{l}\text { Sample } \\
\text { Size }\end{array}$ & $\begin{array}{l}\text { Age } \\
\text { (Years) }\end{array}$ & $\begin{array}{l}\text { Gender } \\
(M / F)\end{array}$ \\
\hline $\begin{array}{l}\text { Hochart } \\
2011^{21}\end{array}$ & France & $\begin{array}{l}\text { Single-center } \\
\text { retrospective } \\
\text { study }\end{array}$ & $\begin{array}{l}\text { Acute myeloid leukemia patients } \\
\text { with febrile neutropenia }\end{array}$ & $100 \%$ & $\begin{array}{l}54(67 \\
\text { vancomycin } \\
\text { treatment } \\
\text { courses, } \\
\text { VTCs) }\end{array}$ & $50 \pm 13.6$ & $27 / 27$ \\
\hline $\begin{array}{l}\text { O'Donnell } \\
2011^{16} \\
\text { (conference } \\
\text { abstract) }\end{array}$ & UK & $\begin{array}{l}\text { Single-center } \\
\text { retrospective } \\
\text { study }\end{array}$ & $\begin{array}{l}\text { Bone marrow transplant patients } \\
\text { who experienced an episode of } \\
\text { febrile neutropenia }\end{array}$ & $100 \%$ & 12 & NR & NR \\
\hline $\begin{array}{l}\text { Donovan } \\
2012^{18} \\
\text { (conference } \\
\text { abstract) }\end{array}$ & $\begin{array}{l}\text { United } \\
\text { states }\end{array}$ & $\begin{array}{l}\text { Retrospective } \\
\text { study }\end{array}$ & Neutropenic adult patients & $100 \%$ & 198 & NR & NR \\
\hline Vazin $2012^{22}$ & Iran & $\begin{array}{l}\text { Prospective } \\
\text { study }\end{array}$ & $\begin{array}{l}\text { Patients in a hematology-oncology } \\
\text { ward who received at least } 3 \\
\text { successive doses of vancomycin and } \\
\text { had serum vancomycin } \\
\text { concentrations at steady state }\end{array}$ & $88 \%$ & 58 & $36.58 \pm 14.33$ & $44 / 14$ \\
\hline $\begin{array}{l}\text { Ghehi } \\
2013^{20}\end{array}$ & Iran & $\begin{array}{l}\text { Single-center } \\
\text { prospective } \\
\text { study }\end{array}$ & $\begin{array}{l}\text { Adults receiving vancomycin for } \\
\text { neutropenic fever after HSCT }\end{array}$ & $100 \%$ & 46 & $32.9 \pm 12.45$ & $30 / 16$ \\
\hline Luo $2014^{17}$ & Canada & $\begin{array}{l}\text { Single-center } \\
\text { prospective } \\
\text { study }\end{array}$ & $\begin{array}{l}\text { Leukemia/bone marrow transplant } \\
\text { outpatients (at least two doses of } \\
\text { vancomycin) }\end{array}$ & $42 \%$ & 48 & $54.5^{\mathrm{b}}$ & $24 / 24$ \\
\hline $\begin{array}{l}\text { Vermis } \\
2014^{19} \\
\text { (conference } \\
\text { abstract) }\end{array}$ & Belgium & $\begin{array}{l}\text { Single-center } \\
\text { retrospective } \\
\text { study }\end{array}$ & $\begin{array}{l}\text { Patients with hematologic } \\
\text { malignancies }\end{array}$ & $72 \%$ & $\begin{array}{l}96(112 \\
\text { VTCs) }\end{array}$ & NR & NR \\
\hline
\end{tabular}

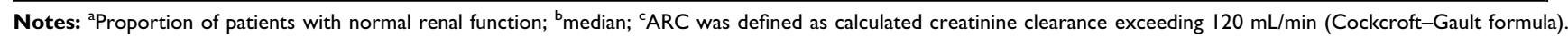
Abbreviations: NR, not reported; HSCT, hematopoietic stem cell transplantation; VTC, vancomycin treatment course; ARC, augmented renal clearance.

\section{Discussion}

\section{Brief Summary of the Systematic Review}

Several descriptive studies demonstrated that their routine vancomycin dosing was inadequate for effective antimicrobial therapy. Regarding the alterations in PK parameters, studies showed that CLva tended to be higher in patients with hematologic malignancies or during febrile neutropenia, whereas $\mathrm{V}$ seemed to be comparable to the control groups. Although several pharmacokinetic models have been developed and a few dosing regimens have been proposed, there is still no consensus on initial vancomycin dosing in patients with hematologic malignancies or neutropenia. The available evidence indicates that TDM and optimal 


\begin{tabular}{|c|c|c|c|c|}
\hline Weight (kg) & $\begin{array}{l}\text { Renal } \\
\text { Function }\end{array}$ & $\begin{array}{l}\text { Vancomycin Dosing } \\
\text { Regimen }\end{array}$ & Timing of Serum Vancomycin & Summary of Results \\
\hline $73 \pm 18.1$ & $\begin{array}{l}107.5 \pm \\
35.4 \mathrm{~mL} / \mathrm{min}\end{array}$ & $\begin{array}{l}\text { Continuous infusion; } \\
\text { loading dose: } 15.5 \pm \\
3.3 \mathrm{mg} / \mathrm{kg} \text {; } \\
\text { maintenance dose: } \\
35.4 \pm 6.9 \mathrm{mg} / \mathrm{kg} / \mathrm{d}\end{array}$ & $\begin{array}{l}\text { At } 24 \text { hours for patients with } \\
\text { a loading dose and } 48 \text { hours for } \\
\text { patients without any loading dose. }\end{array}$ & $\begin{array}{l}\text { - the target serum level for continuous infusion } \\
\text { was greater than } 20 \mathrm{mg} / \mathrm{L} \text {, and only } 6 \text { (I2\%) } \\
\text { cases achieved the target }\end{array}$ \\
\hline NR & NR & NR & At 24 hours, then twice weekly. & $\begin{array}{l}-32 \% \text { of trough levels were subtherapeutic } \\
(<5 \mathrm{mg} / \mathrm{L}) \text {. }\end{array}$ \\
\hline NR & NR & $\begin{array}{l}\text { Intermittent infusion; } \\
15-20 \mathrm{mg} / \mathrm{kg} / \text { dose } \\
\text { and administration } \\
\text { times are determined } \\
\text { by renal function }\end{array}$ & NR & $\begin{array}{l}-25.3 \% \text { of patients achieved therapeutic trough } \\
\text { concentrations }(15-20 \mathrm{mg} / \mathrm{L})\end{array}$ \\
\hline $68.05 \pm 12.61$ & $57 / 58(98.2 \%)^{a}$ & $\begin{array}{l}\text { Intermittent infusion; } \\
\text { Correcting dosage } \\
\text { based on creatinine } \\
\text { clearance was given to } \\
10(17.23 \%) \text { of the } \\
\text { patients }\end{array}$ & $\begin{array}{l}\text { Blood samples were taken from } \\
\text { the patients who received } \\
\text { vancomycin for } 3 \text { consecutive } \\
\text { days, and just before the } \\
\text { administration of the next dose. }\end{array}$ & $\begin{array}{l}\text { - vancomycin trough serum concentration } \\
\text { range was } 15.59 \pm 13.02 \mathrm{mg} / \mathrm{L} \\
\text { - subtherapeutic trough level }(<10 \mathrm{mg} / \mathrm{L}) \text { was } \\
\text { detected in } 3.6 \% \text { of patients } \\
\text { - } 53.3 \% \text { had a level above the maximum } \\
\text { therapeutic concentration }\end{array}$ \\
\hline $74.8 \pm 16.6$ & $\begin{array}{l}102.5 \pm \\
35.33 \mathrm{~mL} / \mathrm{min}\end{array}$ & $\begin{array}{l}\text { Intermittent infusion; } \\
31.9( \pm 10.5) \mathrm{mg} / \mathrm{kg} / \mathrm{d}\end{array}$ & $\begin{array}{l}\text { Within } 30 \text { minutes prior to the } \\
\text { fourth dose }\end{array}$ & $\begin{array}{l}\text { - } 25(54.3 \%) \text { patients had trough } \\
\text { concentrations of }<10 \mathrm{mg} / \mathrm{L} \\
\text { - } 6 \text { patients }(13 \%) \text { had trough levels of }<5 \mathrm{mg} / \mathrm{L}\end{array}$ \\
\hline NR & $77 \mu \mathrm{mol} / \mathrm{L}^{\mathrm{b}}$ & $\begin{array}{l}\text { Intermittent infusion; } \\
\text { once-daily }(2073 \pm \\
338 \mathrm{mg} / \mathrm{d})\end{array}$ & NR & $\begin{array}{l}\text { - } 10(21 \%) \text { patients had therapeutic vancomycin } \\
\text { trough concentrations (i.e., greater than } 10 \mathrm{mg} / \\
\text { L) }\end{array}$ \\
\hline NR & NR & $\begin{array}{l}\text { Continuous infusion; } \\
\text { loading dose: } 15 \mathrm{mg} / \\
\mathrm{kg} \text {, maintenance dose: } \\
30 \mathrm{mg} / \mathrm{kg} / \mathrm{d}\end{array}$ & NR & $\begin{array}{l}\text { - } A R C^{c} \text { was observed in } 73 \mathrm{VTC} \text { with an } \\
\text { average renal clearance of } 147.0 \mathrm{~mL} / \mathrm{min} \text { versus } \\
79.0 \mathrm{~mL} / \mathrm{min} \text {. } \\
\text { - Therapeutic vancomycin levels }(20 \mathrm{mg} / \mathrm{L} \text { ) } \\
\text { were obtained on day } 5 \text { (median) with an } \\
\text { average vancomycin maintenance dose of } \\
41.7 \mathrm{mg} / \mathrm{kg} / \text { day when } A R C \text { was present versus } \\
32.7 \mathrm{mg} / \mathrm{kg} / \text { day on day } 3 .\end{array}$ \\
\hline
\end{tabular}

pharmacokinetic interpretation can help in decreasing the risk of nephrotoxicity.

\section{Implications for Clinical Practice}

In view that standard dosing is inadequate for some patients with hematologic malignancies or neutropenia, improper dosing should be considered as a possible rea- son when clinical improvement was not achieved in these patients with suspected or documented Gram-positive infection. Therefore, optimization of dosing regimen must be considered in both initial dosing and dose adjustment. However, it still remains a question of how to identify the patients with ARC accurately, which makes the individualization of initial dosing difficultly. For 
Table 2 The Characteristic of Comparative Studies

\begin{tabular}{|c|c|c|c|c|c|c|c|c|c|}
\hline \multirow[t]{2}{*}{$\begin{array}{l}\text { Author } \\
\text { (Year) }\end{array}$} & \multirow[t]{2}{*}{ Country } & \multirow[t]{2}{*}{$\begin{array}{l}\text { Study } \\
\text { Design }\end{array}$} & \multirow[t]{2}{*}{$\begin{array}{l}\text { Characteristics } \\
\text { of Patients } \\
\text { Included }\end{array}$} & \multirow[t]{2}{*}{$\begin{array}{l}\text { Sample } \\
\text { Size }\end{array}$} & \multicolumn{2}{|l|}{ Grouping } & \multirow[t]{2}{*}{$\begin{array}{l}\text { Gender } \\
\text { (M/F) }\end{array}$} & \multicolumn{2}{|l|}{$\begin{array}{l}\text { Age } \\
\text { (Years) }\end{array}$} \\
\hline & & & & & $\begin{array}{l}\text { Study } \\
\text { Group }\end{array}$ & Control Group & & $\begin{array}{l}\text { Study } \\
\text { Group }\end{array}$ & $\begin{array}{l}\text { Control } \\
\text { Group }\end{array}$ \\
\hline \multicolumn{10}{|c|}{ Neutropenic patients vs non-neutropenic patients } \\
\hline \multirow[t]{2}{*}{$\begin{array}{l}\text { Haeseker } \\
2014^{25}\end{array}$} & \multirow[t]{2}{*}{ Netherlands } & \multirow[t]{2}{*}{$\begin{array}{l}\text { Single-center } \\
\text { prospective } \\
\text { study }\end{array}$} & \multirow{2}{*}{$\begin{array}{l}\text { Adults received } \\
\text { vancomycin } \\
\text { intravenously and } \\
\text { had at least two } \\
\text { plasma samples }\end{array}$} & 171 & $\begin{array}{l}\text { Neutropenia } \\
\left(<500 / \mathrm{mm}^{3}\right) \text { : } \\
\mathrm{n}=56\end{array}$ & $\begin{array}{l}\text { Non-neutropenia: } \\
n=115\end{array}$ & $104 / 67$ & $55 \pm 13$ & $61 \pm 14$ \\
\hline & & & & $\begin{array}{l}68 \text { (a subset } \\
\text { of patients } \\
\text { with } \\
\text { hematologic } \\
\text { malignancies) }\end{array}$ & $\begin{array}{l}\text { Neutropenia } \\
\left(<500 / \mathrm{mm}^{3}\right) \text { : } \\
\mathrm{n}=55\end{array}$ & $\begin{array}{l}\text { Non-neutropenia: } \\
n=13\end{array}$ & NR & NR & NR \\
\hline Choi $2017^{23}$ & Korea & $\begin{array}{l}\text { Single-center } \\
\text { retrospective } \\
\text { study }\end{array}$ & $\begin{array}{l}\text { Adults receiving } \\
\text { routine TDM of } \\
\text { vancomycin } \\
\text { (trough and } \\
\text { peak). }\end{array}$ & 1307 & $\begin{array}{l}\text { Neutropenia } \\
\left(<500 / \mathrm{mm}^{3}\right) \\
n=162\end{array}$ & $\begin{array}{l}\text { Non-neutropenia: } \\
n=1 / 45\end{array}$ & $728 / 579$ & $54(37-65)^{\#}$ & $56(45-64)^{\#}$ \\
\hline \multicolumn{10}{|c|}{ Patients with hematologic malignancies vs non-cancer patients } \\
\hline $\begin{array}{l}\text { Al-Kofide } \\
2009^{24}\end{array}$ & Saudi Arabia & $\begin{array}{l}\text { Single-center } \\
\text { retrospective } \\
\text { study }\end{array}$ & $\begin{array}{l}\text { Adults receiving } \\
\text { vancomycin } \\
\text { therapy }\end{array}$ & 31 & $\begin{array}{l}\text { Cancer } \\
\text { patients } \\
\text { (proportion } \\
\text { of patients } \\
\text { with } \\
\text { hematologic } \\
\text { malignancies } \\
\text { was } 88.9 \% \text { ): } \\
\mathrm{n}=18\end{array}$ & $\begin{array}{l}\text { Patients without } \\
\text { cancer: } n=13\end{array}$ & NR & $48.5 \pm 20.2$ & $43.4 \pm 22.1$ \\
\hline $\begin{array}{l}\text { Izumisawa } \\
2019^{37}\end{array}$ & Japan & $\begin{array}{l}\text { Retrospective } \\
\text { cohort study }\end{array}$ & $\begin{array}{l}\text { Adults receiving } \\
>3 \text { days of } \\
\text { vancomycin } \\
\text { therapy }\end{array}$ & 522 & $\begin{array}{l}\text { Hematologic } \\
\text { malignancy } \\
\text { patients: } \\
\mathrm{n}=261\end{array}$ & $\begin{array}{l}\text { Non-malignancy } \\
\text { patients: } n=261\end{array}$ & $321 / 201$ & $65.6 \pm 13.6$ & $67.2 \pm 16.9$ \\
\hline
\end{tabular}

Notes: \#Median (interquartile range); ${ }^{2}$ proportion of patients with hematologic malignancy; ${ }^{\mathrm{b} p r o p o r t i o n}$ of patients with neutropenia; ' the absolute count of neutrophils. Abbreviations: NR, not reported; $V$, volume of distribution; $V s s$, volume of distribution at steady state; CLva, vancomycin clearance; $t_{1 / 2}$, half-life; TDM, therapeutic drug monitoring.

example, Soto et $\mathrm{al}^{31}$ and Le Normand et $\mathrm{al}^{28}$ demonstrated that the correlation between estimated $\mathrm{CL}_{\mathrm{CR}}$ and CLva was poor. Haeseker et $\mathrm{al}^{41}$ also showed that CLva algorithms based on estimated $\mathrm{CL}_{\mathrm{CR}}$ were unsuitable in these patients. Additionally, Taghizadeh-Ghehi et $\mathrm{al}^{32}$ demonstrated that none of the seven most cited vancomycin one-compartment models performed well to calculate initial dosage. In this case, TDM of vancomycin could be valuable in patients with hematologic malignan- cies or neutropenia. Without performing TDM, the extremely high dosing could not be administered. Furthermore, previous studies demonstrated that pharmacokinetic dosing programs using measured vancomycin serum levels could predict vancomycin levels with acceptable accuracy and precision. ${ }^{42}$ Therefore, we recommend, when possible, TDM-guided therapy to optimize vancomycin therapy in patients with hematologic malignancy or neutropenia. Above all, the systematic review 


\begin{tabular}{|c|c|c|c|c|c|c|c|c|c|}
\hline \multicolumn{2}{|l|}{ Weight (kg) } & \multicolumn{2}{|c|}{$\begin{array}{l}\text { Patients with } \\
\text { Hematologic } \\
\text { Malignancies/ } \\
\text { Neutropenia n(\%) }\end{array}$} & \multicolumn{2}{|c|}{ Renal Function } & \multirow[t]{2}{*}{$\begin{array}{l}\text { Vancomycin } \\
\text { Dosing } \\
\text { Regimen }\end{array}$} & \multirow[t]{2}{*}{$\begin{array}{l}\text { Timing of } \\
\text { Serum } \\
\text { Vancomycin }\end{array}$} & \multirow[t]{2}{*}{$\begin{array}{l}\text { Determination of } \\
\text { Pharmacokinetic } \\
\text { Parameters }\end{array}$} & \multirow[t]{2}{*}{ Outcomes } \\
\hline $\begin{array}{l}\text { Study } \\
\text { Group }\end{array}$ & $\begin{array}{l}\text { Control } \\
\text { Group }\end{array}$ & $\begin{array}{l}\text { Study } \\
\text { Group }\end{array}$ & $\begin{array}{l}\text { Control } \\
\text { Group }\end{array}$ & $\begin{array}{l}\text { Study } \\
\text { Group }\end{array}$ & $\begin{array}{l}\text { Control } \\
\text { Group }\end{array}$ & & & & \\
\hline NR & NR & $\begin{array}{l}55 / 56 \\
(98.2 \%)^{\mathrm{a}}\end{array}$ & $\begin{array}{l}13 / 115 \\
(11.3 \%)^{\mathrm{a}}\end{array}$ & $\begin{array}{l}1 \mathrm{l} 3 \pm 57 \\
\mathrm{~mL} / \mathrm{min}\end{array}$ & $\begin{array}{l}107 \pm 78 \\
\mathrm{~mL} / \mathrm{min}\end{array}$ & \multirow{2}{*}{$\begin{array}{l}\text { Intermittent } \\
\text { infusion; } \\
\text { an initial loading } \\
\text { dose of } 15 \mathrm{mg} / \mathrm{kg} \\
+ \text { dose } \\
\text { individualization } \\
\text { based on TDM } \\
\text { and renal function. }\end{array}$} & \multirow{2}{*}{$\begin{array}{l}\text { Two plasma } \\
\text { samples (peak } \\
\text { and trough } \\
\text { concentration) }\end{array}$} & \multirow{2}{*}{$\begin{array}{l}\text { Maximum } \\
\text { a posterior (MAP) } \\
\text { Bayesian estimation } \\
\text { (MW/Pharm 3.60, } \\
\text { Mediware, the } \\
\text { Netherlands) }\end{array}$} & \multirow[t]{2}{*}{ CLva, V } \\
\hline NR & $N R$ & $55(100 \%)^{\mathrm{a}}$ & $\begin{array}{l}13 \\
(100 \%)^{a}\end{array}$ & $\begin{array}{l}114 \pm 57 \\
\mathrm{~mL} / \mathrm{min}\end{array}$ & $\begin{array}{l}\mathrm{III} \pm 58 \\
\mathrm{~mL} / \mathrm{min}\end{array}$ & & & & \\
\hline $\begin{array}{l}62.0 \\
(56.0-70.0)^{\#}\end{array}$ & $\begin{array}{l}60.0 \\
(53.0-68.7)^{\#}\end{array}$ & $135(83.3 \%)^{\mathrm{a}}$ & $\begin{array}{l}184 \\
(16.1 \%)^{\mathrm{a}}\end{array}$ & $\begin{array}{l}0.6 \\
(0.5-0.8) \\
{ }^{\#} \mathrm{mg} / \mathrm{dL}\end{array}$ & $\begin{array}{l}0.7 \\
(0.5-0.9) \\
{ }^{\#} \mathrm{mg} / \mathrm{dL}\end{array}$ & $\begin{array}{l}\text { Intermittent } \\
\text { infusion; } 1000 \mathrm{mg} \\
\text { vancomycin every } \\
12 \mathrm{~h}\end{array}$ & $\begin{array}{l}\text { Steady-state } \\
\text { serum } \\
\text { vancomycin } \\
\text { concentration } \\
\text { (after at least the } \\
\text { fourth dose) }\end{array}$ & $\begin{array}{l}\text { Posterior Bayesian } \\
\text { estimation (Abbott's } \\
\text { PKS software) }\end{array}$ & $\begin{array}{l}\text { Serum trough } \\
\text { vancomycin } \\
\text { concentration } \\
\text { at steady state, } \\
\mathrm{t}_{1 / 2}\end{array}$ \\
\hline $66.7 \pm 17.1$ & $68.9 \pm 14$ & $N R^{b}$ & $N R^{b}$ & $\begin{array}{l}105.4 \pm \\
62.3 \mathrm{~mL} / \\
\min \end{array}$ & $\begin{array}{l}87.2 \pm \\
27.5 \mathrm{~mL} / \\
\min \end{array}$ & $\begin{array}{l}\text { Intermittent } \\
\text { infusion; Initial } \\
\text { vancomycin } \\
\text { dosing regimens } \\
\text { were chosen by } \\
\text { attending } \\
\text { physicians }\end{array}$ & $\begin{array}{l}\text { Peak and trough } \\
\text { vancomycin } \\
\text { serum } \\
\text { concentration } \\
\text { (after the third } \\
\text { dose or at steady } \\
\text { state) }\end{array}$ & $\begin{array}{l}\text { Pharmacokinetic } \\
\text { equations }\end{array}$ & CLva, $\mathrm{V}, \mathrm{t}_{1 / 2}$ \\
\hline $55.0 \pm 10.3$ & $56.2 \pm 13.1$ & $\begin{array}{l}1.47 \pm 2.46 \times \\
10^{3} / \mu \mathrm{L}^{\mathrm{c}}\end{array}$ & $\begin{array}{l}7.80 \pm \\
4.66 \times \\
10^{3} / \mu \mathrm{L}^{\mathrm{c}}\end{array}$ & $\begin{array}{l}77.0 \pm \\
29.2 \mathrm{~mL} / \\
\min \end{array}$ & $\begin{array}{l}74.1 \pm \\
35.6 \mathrm{~mL} / \\
\min \end{array}$ & $\begin{array}{l}\text { Intermittent } \\
\text { infusion; } \\
\text { Initial dosing was } \\
\text { not pre-specified }\end{array}$ & $\begin{array}{l}\text { After } \geqq 3 \text { days } \\
\text { following the } \\
\text { start of } \\
\text { administration }\end{array}$ & $\begin{array}{l}\text { Bayesian estimation } \\
\text { using TDM software } \\
\text { Ver } 3.3\end{array}$ & $\begin{array}{l}\text { Trough } \\
\text { concentration, } \\
\text { CLva, Vss, } \mathrm{t}_{1 / 2}\end{array}$ \\
\hline
\end{tabular}

underlines the necessity to perform vancomycin TDM in patients with hematologic malignancies or neutropenia, which might be overlooked previously.

\section{Implications for Further Research}

According to the comprehensive systematic review, several knowledge gaps have been identified, and are summarized as follows:
- The mechanism of the altered PK parameters warrants investigation, which could help us judge whether the phenomenon was deceptive or not.

Two scenarios should be considered to clarify the mechanism of the altered PK parameters. On the one hand is the further research in clinical settings. First, most of the studies did not distinguish whether the change in pharmacokinetic parameters was due to 


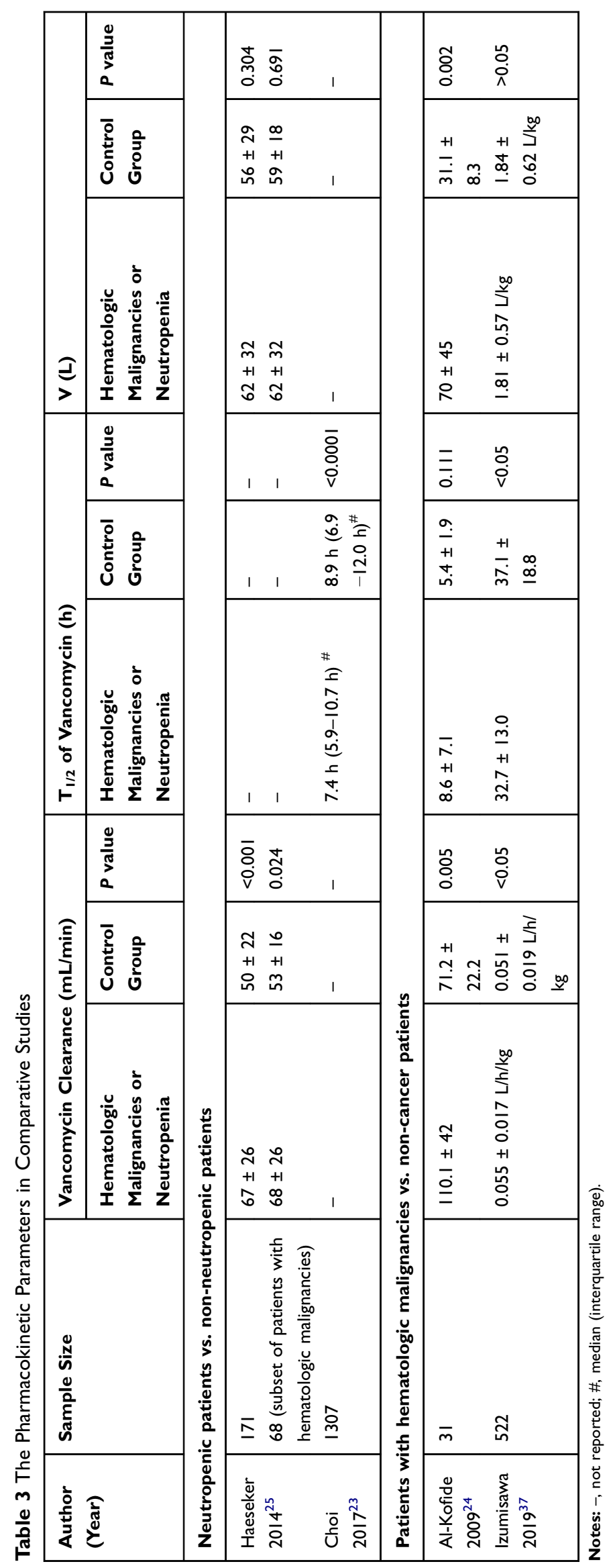


hematologic malignancy or neutropenia. The effect of hematologic malignancy can be complicated by neutropenia and vice versa. Only Haeseker et $\mathrm{al}^{25}$ demonstrated that the augmented clearance was associated with neutropenia rather than hematologic malignancies with a limited sample size. As previous studies showed vancomycin clearance was higher in patients with hematologic malignancies than solid tumors $^{43}$ and the difference between solid malignancies and control groups was attenuated, ${ }^{44}$ we assume that the phenomenon might be explained by different proportions of patients with neutropenia. In other words, it is the neutropenia that affects pharmacokinetic changes per se. Conventional doses of vancomycin may not offer adequate systematic exposure in febrile neutropenic patients rather than hematologic malignancy without neutropenia. Further studies are needed to elucidate the exact effect between hematologic malignancies and neutropenia. Second, studies focused on non-neutropenic immunocompromised states are limited currently. Whether the pharmacokinetic changes exist in non-neutropenic immunocompromised states can help in interpreting the mechanism. Third, none of the studies evaluated the change in measured $\mathrm{CL}_{\mathrm{CR}}$, which might also be helpful for understanding the mechanism and identifying patients with ARC.

On the other hand, the physiological mechanism responsible for ARC has not been well-defined, which can be investigated using in vitro studies and animal models. Several assumptions have been put up, including: (1) possible changes in renal function and urine flow can be induced by cancer, systematic inflammation and increased intravenous fluid; (2) tubular secretion apart from glomerular filtration; (3) non-renal elimination of vancomycin, such as hepatic conjugation; (4) cancer and neutropenia could enhance vascular permeability, which would induce increased vancomycin extravasation and low serum concentrations. ${ }^{20,23-25,28,29}$ The above assumptions require further exploration.

- No PPK model has been developed in patients with hematologic malignancies and concomitant neutropenia, which could help with determining individualized initial dose.

- The optimization of vancomycin dosing in patients with hematologic malignancies or neutropenia requires further research. For example, prospective validation of vancomycin initial dosing regimens, stages of enhanced $\mathrm{CL}_{\mathrm{CR}}$ and a consensus of initial dosing strategies are urgently needed worldwide.

- Few studies on the PKs of vancomycin in patients with hematologic malignancies or neutropenia reported clinical outcomes. Taking safety endpoints as an example, some studies illustrated that patients with hematologic malignancies may be vulnerable to nephrotoxicity. ${ }^{45,46}$ In this case, the target trough concentration for these patients might be different from other patients and require further research. Indeed, it should be noted that the establishment of the relationship between accelerated vancomycin elimination and outcomes of clinical effectiveness is difficult due to the complexity of these patients.

\section{Strengths and Limitations}

To our knowledge, this is the first comprehensive review concerning vancomycin dosing optimization in patients with hematologic malignancy or neutropenia. Additionally, the characteristics and the key results of each individual study are presented in Tables 1-4, which can provide specific details for physicians, pharmacists as well as researchers. However, as the available evidence to date was limited and diverse, no quantitative analysis was performed. Clinical heterogeneity existed across studies. For example, patients included had different types of hematologic malignancies and no consistent definition of neutropenia has been applied among studies. Nevertheless, we consider that this systematic review maps the relevant literature on this topic, allowing us to pay attention to the optimization of vancomycin dosing in patients with hematologic malignancy or neutropenia.

\section{Conclusion}

The available evidence indicates that conventional vancomycin dosing leads to suboptimal concentration in patients with hematologic malignancy or neutropenia. TDM accompanied by pharmacokinetic interpretation can decrease the risk of nephrotoxicity. The individualization of the initial dosing regimen and mechanisms of augmented clearance require further research. 
Table 4 Characteristics and Results of Studies for Developing PK/PPK Models

\begin{tabular}{|c|c|c|c|c|c|c|c|c|c|}
\hline $\begin{array}{l}\text { Author } \\
\text { (Year) }\end{array}$ & Country & $\begin{array}{l}\text { Study } \\
\text { Design }\end{array}$ & $\begin{array}{l}\text { Characteristics of } \\
\text { Patients Included }\end{array}$ & $\begin{array}{l}\text { Patients } \\
\text { with } \\
\text { Neutro } \\
\text { penia } \\
\text { (\%) }\end{array}$ & $\begin{array}{l}\text { Sample } \\
\text { Size }\end{array}$ & $\begin{array}{l}\text { Number } \\
\text { of serum } \\
\text { Concen } \\
\text { trations }\end{array}$ & Age & $\begin{array}{l}\text { Gender } \\
\text { (M/F) }\end{array}$ & $\begin{array}{l}\text { Weight } \\
\text { (kg) }\end{array}$ \\
\hline \multicolumn{10}{|c|}{ Pharmacokinetic analysis } \\
\hline $\begin{array}{l}\text { Kureishi } \\
1990^{26}\end{array}$ & Canada & $\begin{array}{l}\text { Single-center } \\
\text { prospective } \\
\text { study }\end{array}$ & $\begin{array}{l}\text { Patients with acute } \\
\text { leukemia and had } \\
\text { absolute granulocyte } \\
\text { below } 500 / \mathrm{mm}^{3}\end{array}$ & $100 \%$ & 25 & NR & NR & NR & NR \\
\hline $\begin{array}{l}\text { Le } \\
\text { Normand } \\
1994^{28}\end{array}$ & France & $\begin{array}{l}\text { Single-center } \\
\text { prospective } \\
\text { study }\end{array}$ & $\begin{array}{l}\text { Patients with } \\
\text { hematologic } \\
\text { malignancies who } \\
\text { were neutropenic } \\
\left(100 / \mathrm{mm}^{3}\right)\end{array}$ & $100 \%$ & 10 & 130 & $\begin{array}{l}36.2 \text { (range: } \\
18-50)\end{array}$ & $4 / 6$ & $64.6 \pm 10.4$ \\
\hline $\begin{array}{l}\text { Jarkowski } \\
2011^{27}\end{array}$ & $\begin{array}{l}\text { United } \\
\text { states }\end{array}$ & $\begin{array}{l}\text { Single-center } \\
\text { prospective } \\
\text { study }\end{array}$ & $\begin{array}{l}\text { Acute myeloid } \\
\text { leukemia patients } \\
\text { receiving vancomycin }\end{array}$ & NR & 25 & NR & $59.12 \pm 16.26$ & $17 / 8$ & $86.05 \pm 19.42$ \\
\hline $\begin{array}{l}\text { Ghehi } \\
2013^{20}\end{array}$ & Iran & $\begin{array}{l}\text { Single-center } \\
\text { prospective } \\
\text { study }\end{array}$ & $\begin{array}{l}\text { Patients with } \\
\text { neutropenic fever after } \\
\text { HSCT }\end{array}$ & $100 \%$ & 20 & 40 & $29.9 \pm 9.5$ & NR & $\begin{array}{l}72.5 \pm 15.2 \\
(A B W)\end{array}$ \\
\hline \multicolumn{10}{|c|}{ Population pharmacokinetic model } \\
\hline $\begin{array}{l}\text { Buelga } \\
2005^{29}\end{array}$ & Spain & $\begin{array}{l}\text { Single-center } \\
\text { retrospective } \\
\text { study }\end{array}$ & $\begin{array}{l}\text { Adult inpatients with } \\
\text { an underlying } \\
\text { hematologic } \\
\text { malignancy }\end{array}$ & $43.7 \%$ & 215 & 1004 & $51.5 \pm 15.9$ & $119 / 96$ & $64.7 \pm 11.3$ \\
\hline $\begin{array}{l}\text { Okada } \\
2018^{38}\end{array}$ & Japan & $\begin{array}{l}\text { Single-center } \\
\text { retrospective } \\
\text { study }\end{array}$ & $\begin{array}{l}\text { Patients undergoing } \\
\text { allo-HSCT who } \\
\text { received preventive } \\
\text { treatment with } \\
\text { vancomycin }\end{array}$ & NR & 75 & 227 & $\begin{array}{l}49 \text { (range: } \\
17-69)\end{array}$ & $49 / 26$ & $\begin{array}{l}59.4 \\
\text { (range: } 39 . \\
4-104.5)\end{array}$ \\
\hline $\begin{array}{l}\text { Bury } \\
2019^{36}\end{array}$ & $\begin{array}{l}\text { The } \\
\text { Netherlands }\end{array}$ & $\begin{array}{l}\text { Retrospective } \\
\text { matched } \\
\text { cohort study }\end{array}$ & $\begin{array}{l}\text { Intravenous } \\
\text { vancomycin therapy } \\
\text { for } \geq 2 \text { days and at } \\
\text { least one available } \\
\text { vancomycin } \\
\text { concentration }\end{array}$ & $26.7 \%$ & 116 & 742 & $61.4 \pm 13.4$ & $67 / 49$ & NR \\
\hline
\end{tabular}

Abbreviations: $\mathrm{V}$, volume of distribution; $\mathrm{CL}$, clearance; Ke, elimination rate constant; $\mathrm{t}_{1 / 2}$, half-life; NR, not reported; $\mathrm{ABW}$, adjusted body weight; TBW, total body weight; $\mathrm{CL}_{\mathrm{CR}}$, creatinine clearance; $\mathrm{Vc}$, volume of central compartment; $\mathrm{Vss}$, steady-state volume of distribution; $\mathrm{V}_{\mathrm{p}}$, distribution volume of peripheral compartment. 


\begin{tabular}{|c|c|c|c|c|c|c|c|c|}
\hline \multirow[t]{2}{*}{ Renal Function } & \multirow{2}{*}{$\begin{array}{l}\text { Vancomycin } \\
\text { Dosing }\end{array}$} & \multirow{2}{*}{$\begin{array}{l}\text { Timing of Vancomycin } \\
\text { Sampling }\end{array}$} & \multirow{2}{*}{$\begin{array}{l}\text { Pharmacokinetic } \\
\text { Modeling Method }\end{array}$} & \multirow[t]{2}{*}{ Model } & \multicolumn{4}{|c|}{ Pharmacokinetic Parameters } \\
\hline & & & & & $\mathbf{v}$ & CL & $\begin{array}{l}\text { Ke } \\
\left(\mathbf{h}^{-1}\right)\end{array}$ & $t_{1 / 2}(h)$ \\
\hline NR & $\begin{array}{l}\text { Intermittent } \\
\text { infusion; } \\
15 \mathrm{mg} / \mathrm{kg} \text { q } 12 \mathrm{~h}\end{array}$ & $\begin{array}{l}\text { Prior to infusion and at } \mathrm{I} \text { and } \\
3 \mathrm{~h} \text { post-infusion daily during } \\
\text { the first } 3 \text { days and every } 3 \text { to } \\
7 \text { days thereafter }\end{array}$ & $\begin{array}{l}\text { Equations with two } \\
\text { steady-state } \\
\text { samples }\end{array}$ & $\begin{array}{l}\text { One- } \\
\text { compartment model }\end{array}$ & $\begin{array}{l}0.61 \pm 0.21 \\
\mathrm{~L} / \mathrm{kg}\end{array}$ & NR & $N R$ & $5.6 \pm 1.8$ \\
\hline $141.2 \pm 36.2 \mathrm{~mL} / \mathrm{min}$ & $\begin{array}{l}\text { Intermittent } \\
\text { infusion; } \\
1000 \mathrm{mg} \text { every } \\
12 \mathrm{~h}\end{array}$ & $\begin{array}{l}\text { The first dose: prior to } \\
\text { injection, at the end of the } \\
\text { infusion, and II samples } \\
\text { collected until II h after the } \\
\text { end of the infusion }\end{array}$ & $\begin{array}{l}\text { G-Pharm computer } \\
\text { program }\end{array}$ & $\begin{array}{l}\text { Two- } \\
\text { compartment model }\end{array}$ & $\begin{array}{l}\text { Vc: } 22.9 \pm \\
\text { II. } 4 \mathrm{~L}\end{array}$ & $\begin{array}{l}158 \pm 5 \mid \\
\mathrm{mL} / \mathrm{min}\end{array}$ & NR & $\begin{array}{l}2.94 \pm \\
0.84\end{array}$ \\
\hline $\begin{array}{l}85.72 \pm 37.28 \mathrm{~mL} / \\
\mathrm{min} / 1.73 \mathrm{~m}^{2}\end{array}$ & $\begin{array}{l}\text { Intermittent } \\
\text { infusion; } \\
1970.00 \pm \\
605.19 \mathrm{mg} / \mathrm{d}\end{array}$ & $\begin{array}{l}\text { Three samples: I h, 3-8 h, } \\
\text { and 8-24 h post-infusion }\end{array}$ & $\begin{array}{l}\text { Maximum a priori } \\
\text { Bayesian estimation } \\
\text { using Adapt } 5\end{array}$ & $\begin{array}{l}\text { Two-compartment } \\
\text { model }\end{array}$ & $\begin{array}{l}\text { Vc: } 0.23 \\
L / k g \\
\text { Vss: } 0.60 \\
L / k g\end{array}$ & $0.14 \mathrm{~L} / \mathrm{h} / \mathrm{kg}$ & NR & NR \\
\hline $104.7 \pm 37.0 \mathrm{~mL} / \mathrm{min}$ & $\begin{array}{l}\text { Intermittent } \\
\text { infusion; } 31.9 \\
( \pm 10.5) \mathrm{mg} / \mathrm{kg} / \\
\mathrm{d}(69.6 \%: \mathrm{lg} \\
\text { q/2h; } \\
17.4 \%: \mathrm{lg} 98 \mathrm{~h})\end{array}$ & $\begin{array}{l}\text { First steady-state trough } \\
\text { (within } 30 \text { minutes prior to } \\
\text { the fourth dose), peak } \\
\text { concentration, random } \\
\text { sample }\end{array}$ & $\begin{array}{l}\text { Equations with two } \\
\text { steady-state } \\
\text { samples }\end{array}$ & $\begin{array}{l}\text { One-compartment } \\
\text { model }\end{array}$ & $\begin{array}{l}0.60 \\
(0.44-0.76) \\
\mathrm{L} / \mathrm{kg}\end{array}$ & $\begin{array}{l}0.090 \\
(0.071- \\
0.109) \\
\mathrm{L} / \mathrm{h} / \mathrm{kg} \\
109.7 \\
(82.7- \\
136) \\
\mathrm{mL} / \mathrm{min}\end{array}$ & $\begin{array}{l}0.16 \\
(0.13- \\
0.19)\end{array}$ & $\begin{array}{l}4.9 \\
(3.8-6.0)\end{array}$ \\
\hline $89.4 \pm 39.2 \mathrm{~mL} / \mathrm{min}$ & $\begin{array}{l}\text { Intermittent } \\
\text { infusion }\end{array}$ & $\begin{array}{l}\text { Blood sampling was ordered } \\
\text { as required clinically }\end{array}$ & $\begin{array}{l}\text { Nonlinear mixed- } \\
\text { effect modeling } \\
\text { approach } \\
\text { (NONMEM) }\end{array}$ & $\begin{array}{l}\text { One-compartment } \\
\text { model }\end{array}$ & $\begin{array}{l}C L(L / h): 1 . C \\
C V_{C L}: 28.16 \\
V(L)=0.98\end{array}$ & $\begin{array}{l}\times \mathrm{CL}_{\mathrm{CR}}(\mathrm{Coc} \\
\mathrm{TBW} ; \mathrm{CV}_{\mathrm{v}}: 37\end{array}$ & ft and $G$ & ult) (L/h); \\
\hline $\begin{array}{l}113 \text { (range: } \\
47-253) \mathrm{mL} / \mathrm{min}\end{array}$ & $\begin{array}{l}\text { Intermittent } \\
\text { infusion } \\
\text { initial dosage } \\
\text { of I } \mathrm{g} / 12 \\
\text { hours (if the } \\
\mathrm{CL}_{\mathrm{CR}} \text { was } \\
>75 \mathrm{~mL} / \mathrm{min} / \\
1.73 \mathrm{~m} 2 \text { ). }\end{array}$ & $\begin{array}{l}\text { Immediately before ad- } \\
\text { ministering } \\
\text { vancomycin,I hour after drug } \\
\text { administration and at some } \\
\text { other points as necessary }\end{array}$ & $\begin{array}{l}\text { Nonlinear mixed- } \\
\text { effect modeling } \\
\text { approach } \\
\text { (NONMEM) }\end{array}$ & $\begin{array}{l}\text { Two-compartment } \\
\text { model }\end{array}$ & $\begin{array}{l}V_{c}(L)=39.2 \\
C L(L / h)=4 . \\
V_{P}(L)=56.1\end{array}$ & $\begin{array}{l}(\mathrm{TBW} / 59.4)^{\prime} \\
5 \times\left(\mathrm{CL}_{\mathrm{CR}} / 1 \mathrm{I3}\right. \\
\mathrm{CV}_{V_{\mathrm{P}}}=66.9 \%\end{array}$ & $\begin{array}{l}8 ; \mathrm{CV}_{\mathrm{Vc}}= \\
70 ; \mathrm{CV}_{\mathrm{C}}\end{array}$ & $\begin{array}{l}4.2 \% \\
=25.2 \%\end{array}$ \\
\hline Median $92.7 \mathrm{~mL} / \mathrm{min}$ & $\begin{array}{l}\text { Intermittent } \\
\text { infusion } \\
\text { The specific } \\
\text { dosing was not } \\
\text { pre-specified }\end{array}$ & NR & $\begin{array}{l}\text { Nonlinear mixed- } \\
\text { effect modeling } \\
\text { (NONMEM) }\end{array}$ & $\begin{array}{l}\text { Two-compartment } \\
\text { model }\end{array}$ & $\begin{array}{l}\mathrm{CL}(\mathrm{L} / \mathrm{h})=3 \\
1.277^{\mathrm{NEUTRC}}\end{array}$ & $\begin{array}{l}2+(1+0.00834 \\
=N I A ; C V_{C L}=33\end{array}$ & $\mathrm{CL}_{\mathrm{CR}}-\mathrm{IC}$ & \\
\hline
\end{tabular}




\section{Acknowledgments}

Thanks for Xiaotong Li's help for risk of bias assessment during the revision process.

\section{Disclosure}

The authors report no conflicts of interest in this work.

\section{References}

1. Matzke GR, Aronoff GR, Atkinson AJ, et al. Drug dosing consideration in patients with acute and chronic kidney disease-a clinical update from Kidney Disease: Improving Global Outcomes (KDIGO). Kidney Int. 2011;80(11):1122-1137. doi:10.1038/ki.2011.322

2. Matsumoto K, Takesue Y, Ohmagari N, et al. Practice guidelines for therapeutic drug monitoring of vancomycin: a consensus review of the Japanese Society of Chemotherapy and the Japanese Society of Therapeutic Drug Monitoring. J Infect Chemother. 2013;19 (3):365-380. doi:10.1007/s10156-013-0599-4

3. Bilbao-Meseguer I, Rodriguez-Gascon A, Barrasa H, Isla A, Solinis MA. Augmented renal clearance in critically Ill patients: a systematic review. Clin Pharmacokinet. 2018;57(9):1107-1121. doi: 10.1007/s40262-018-0636-7

4. Udy AA, Jarrett P, Lassig-Smith M, et al. Augmented renal clearance in traumatic brain injury: a single-center observational study of atrial natriuretic peptide, cardiac output, and creatinine clearance. $J$ Neurotrauma. 2017;34(1):137-144. doi:10.1089/neu.2015.4328

5. Kim AJ, Lee JY, Choi SA, Shin WG. Comparison of the pharmacokinetics of vancomycin in neurosurgical and non-neurosurgical patients. Int J Antimicrob Agents. 2016;48(4):381-387. doi:10.1016/ j.ijantimicag.2016.06.022

6. Keng MK, Sekeres MA. Febrile neutropenia in hematologic malignancies. Curr Hematol Malig Rep. 2013;8(4):370-378. doi:10.1007/s11899-013-0171-4

7. Freifeld AG, Bow EJ, Sepkowitz KA, et al. Clinical practice guideline for the use of antimicrobial agents in neutropenic patients with cancer: 2010 update by the infectious diseases society of america. Clin Infect Dis. 2011;52(4):e56-e93.

8. Goulenok T, Fantin B. Antimicrobial treatment of febrile neutropenia: pharmacokinetic-pharmacodynamic considerations. Clin Pharmacokinet. 2013;52(10):869-883. doi:10.1007/s40262-013-0086-1

9. Lortholary O, Lefort A, Tod M, Chomat AM, Darras-Joly C, Cordonnier C. Pharmacodynamics and pharmacokinetics of antibacterial drugs in the management of febrile neutropenia. Lancet Infect Dis. 2008;8(10):612-620. doi:10.1016/S1473-3099(08)70228-7

10. Ye ZK, Chen YL, Chen K, et al. Therapeutic drug monitoring of vancomycin: a guideline of the division of therapeutic drug monitoring, chinese pharmacological society. J Antimicrob Chemother. 2016;71(11):3020-3025. doi:10.1093/jac/dkw254

11. Rybak M, Lomaestro B, Rotschafer JC, et al. Therapeutic monitoring of vancomycin in adult patients: a consensus review of the American Society of Health-System Pharmacists, the Infectious Diseases Society of America, and the Society of Infectious Diseases Pharmacists. Am J Health Syst Pharm. 2009;66(1):82-98. doi:10.2146/ajhp080434

12. Moher D, Liberati A, Tetzlaff J, Altman DG. Preferred reporting items for systematic reviews and meta-analyses: the PRISMA statement. PLoS Med. 2009;6(7):e1000097. doi:10.1371/journal.pmed.1000097

13. Higgins JPT, Green S. Cochrane Handbook for Systematic Reviews of Interventions. Version 5.1.0. Cochrane Collaboration; 2011:1-8.

14. Wells G, Shea B, O'Connell D, et al. The Newcastle-Ottawa Scale (NOS) for assessing the quality if nonrandomized studies in meta-analyses. Available from: http://www.ohri.ca/programs/clini cal_epidemiology/oxford.htm. Accessed May 11, 2020.
15. Kanji S, Hayes M, Ling A, et al. Reporting guidelines for clinical pharmacokinetic studies: the ClinPK statement. Clin Pharmacokinet. 2015;54(7):783-795. doi:10.1007/s40262-015-0236-8

16. O'Donnell R. Audit of BMT antibiotic febrile neutropenia guidelines. Bone Marrow Transplant. 2011;46:S433-S434.

17. Luo C, Hussaini T, Lacaria K, Yeung J, Lau TT, Broady RC. Evaluation of a Once-Daily Vancomycin regimen in an outpatient leukemia/bone marrow transplant clinic (OD-VANCO Study). Can J Hosp Pharm. 2014;67(4):280-285. doi:10.4212/cjhp.v67i4.1372

18. Donovan KA, Sklenicka J. Is a standard vancomycin dosing protocol appropriate to achieve therapeutic trough levels in adult neutropenic patients? Pharmacotherapy. 2012;32(10):e237-e238.

19. Vermis K, Steel E, Vandenbroucke J. Prevalence of augmented renal clearance in haematological patients and the impact on vancomycin dosing. J Oncol Pharm Pract. 2014;20(3):7.

20. Ghehi MT, Rezaee S, Hayatshahi A, et al. Vancomycin pharmacokinetic parameters in patients undergoing Hematopoietic Stem Cell Transplantation (HSCT). Int J Hematol Oncol Stem Cell Res. 2013;7(4):1-9.

21. Hochart C, Berthon C, Corm S, et al. Vancomycin serum concentration during febrile neutropenia in patients with acute myeloid leukemia. Med Mal Infect. 2011;41(12):652-656. doi:10.1016/j. medmal.2011.09.014

22. Vazin A, Japoni A, Shahbazi S, Davarpanah MA. Vancomycin utilization evaluation at hematology-oncology ward of a teaching hospital in iran. Iran J Pharm Res. 2012;11(1):163-170.

23. Choi MH, Choe YH, Lee SG, Jeong SH, Kim JH. Neutropenia is independently associated with sub-therapeutic serum concentration of vancomycin. Clin Chim Acta. 2017;465:106-111. doi:10.1016/j. cca.2016.12.021

24. Al-Kofide H, Zaghloul I, Al-Naim L. Pharmacokinetics of vancomycin in adult cancer patients. J Oncol Pharm Pract. 2010;16 (4):245-250. doi:10.1177/1078155209355847

25. Haeseker MB, Croes S, Neef C, Bruggeman CA, Stolk LM, Verbon A. Vancomycin dosing in neutropenic patients. PLoS One. 2014;9(11):e112008. doi:10.1371/journal.pone.0112008

26. Kureishi A, Jewesson PJ, Bartlett KH, Cole CD, Chow AW. Application of a modified bioassay for monitoring serum teicoplanin and vancomycin in febrile neutropenic patients. Antimicrob Agents Chemother. 1990;34(9):1642-1647. doi:10.1128/AAC.34.9.1642

27. Jarkowski IA, Forrest A, Sweeney RP, et al. Characterization of vancomycin pharmacokinetics in the adult acute myeloid leukemia population. J Oncol Pharm Pract. 2012;18(1):91-96. doi:10.1177/ 1078155211402107

28. Le Normand Y, Milpied N, Kergueris MF, Harousseau JL. Pharmacokinetic parameters of vancomycin for therapeutic regimens in neutropenic adult patients. Int J Biomed Comput. 1994;36(12):121-125. doi:10.1016/0020-7101(94)90102-3

29. Buelga DS,Fernandez de Gatta MM, Herrera EV, Dominguez-Gil A, Garcia MJ. Population pharmacokinetic analysis of vancomycin in patients with hematological malignancies. Antimicrob Agents Chemother. 2005;49(12):4934-4941. doi:10.1128/AAC.49.12.49 34-4941.2005

30. Hirai K, Ishii H, Shimoshikiryo T, et al. Augmented renal clearance in patients with febrile neutropenia is associated with increased risk for subtherapeutic concentrations of vancomycin. Ther Drug Monit. 2016;38(6):706-710. doi:10.1097/FTD.0000000000000346

31. Soto J, Alsar MJ, Chantal P, Sacristan JA. Correlation of vancomycin clearance and creatinine clearance: unreliability for predicting initial dosing in neutropenic haematological patients. $J$ Antimicrob Chemother. 1993;32(6):920-922. doi:10.1093/jac/32.6.920

32. Taghizadeh-Ghehi M, Rezaee S, Gholami K, Hadjibabaie M. Predictive performance of vancomycin population pharmacokinetic models in Iranian patients underwent hematopoietic stem cell transplantation. J Res Pharm Pract. 2015;4(3):129-134. doi:10.410 3/2279-042X.162357 
33. Fernandez de Gatta MM, Santos BD, Sanchez NA, Dominguez-Gil A, Garcia MJ. Vancomycin dosage optimization in patients with malignant haematological disease by pharmacokinetic/pharmacodynamic analysis. Clin Pharmacokinet. 2009;48(4):273-280. doi:10.2165/00003088-200948040-00005

34. Fernandez de Gatta MM, Calvo MV, Hernandez JM, Caballero D, San MJ, Dominguez-Gil A. Cost-effectiveness analysis of serum vancomycin concentration monitoring in patients with hematologic malignancies. Clin Pharmacol Ther. 1996;60(3):332-340. doi:10.1016/S0009-9236(96)90060-0

35. Suzuki Y, Tokimatsu I, Morinaga Y, et al. A retrospective analysis to estimate target trough concentration of vancomycin for febrile neutropenia in patients with hematological malignancy. Clin Chim Acta. 2015;440:183-187. doi:10.1016/j.cca.2014.11.027

36. Bury D, Ter Heine R, van de Garde E, et al. The effect of neutropenia on the clinical pharmacokinetics of vancomycin in adults. Eur J Clin Pharmacol. 2019;75(7):921-928. doi:10.1007/s00228-019-02657-6

37. Izumisawa T, Kaneko T, Soma M, et al. Augmented renal clearance of vancomycin in hematologic malignancy patients. Biol Pharm Bull. 2019;42(12):2089-2094. doi:10.1248/bpb.b19-00652

38. Okada A, Kariya M, Irie K, et al. Population pharmacokinetics of vancomycin in patients undergoing allogeneic hematopoietic stem-cell transplantation. J Clin Pharmacol. 2018;58(9):1140-1149. doi: $10.1002 /$ jcph.1106

39. Matzke GR, Zhanel GG, Guay DR. Clinical pharmacokinetics of vancomycin. Clin Pharmacokinet. 1986;11(4):257-282. doi:10.21 65/00003088-198611040-00001
40. Matzke GR, McGory RW, Halstenson CE, Keane WF. Pharmacokinetics of vancomycin in patients with various degrees of renal function. Antimicrob Agents Chemother. 1984;25(4):433-437. doi:10.1128/AAC.25.4.433

41. Haeseker M, Croes S, Neef C, Bruggeman C, Stolk L, Verbon A. Evaluation of vancomycin prediction methods based on estimated creatinine clearance or trough levels. Ther Drug Monit. 2016;38 (1):120-126. doi:10.1097/FTD.0000000000000250

42. Fernandez de Gatta MM, Fruns I, Dominguez-Gil A. Individualizing vancomycin dosing regimens: an evaluation of two pharmacokinetic dosing programs in critically ill patients. Pharmacotherapy. 1994;14 (2):196-201.

43. Krivoy N, Peleg S, Postovsky S, Ben AM. Pharmacokinetic analysis of vancomycin in steady state in pediatric cancer patients. Pediatr Hematol Oncol. 1998;15(4):333-338. doi:10.3109/08880019809014 017

44. Omote S, Yano Y, Hashida $\mathrm{T}$, et al. A retrospective analysis of vancomycin pharmacokinetics in Japanese cancer and non-cancer patients based on routine trough monitoring data. Biol Pharm Bull. 2009;32(1):99-104. doi:10.1248/bpb.32.99

45. Toro JJ, Diaz-Duque AE, Gass MJ, Haile DJ, Gushiken F. Acute renal injury and vancomycin levels in patients undergoing autologous hematopoietic stem cell transplantation. Biol Blood Marrow Transplant. 2017;23(3):S139. doi:10.1016/j.bbmt.2016.12.269

46. Mae H, Ooi J, Takahashi S, et al. Early renal injury after myeloablative cord blood transplantation in adults. Leuk Lymphoma. 2008;49(3):538-542. doi:10.1080/10428190701824577
Infection and Drug Resistance

\section{Publish your work in this journal}

Infection and Drug Resistance is an international, peer-reviewed openaccess journal that focuses on the optimal treatment of infection (bacterial, fungal and viral) and the development and institution of preventive strategies to minimize the development and spread of resistance. The journal is specifically concerned with the epidemiology of antibiotic resistance and the mechanisms of resistance development and diffusion in both hospitals and the community. The manuscript management system is completely online and includes a very quick and fair peerreview system, which is all easy to use. Visit http://www.dovepress.com/ testimonials.php to read real quotes from published authors. 